\title{
The effect of an NO donor, pentaerythrityl tetranitrate, on biochemical, functional, and morphological attributes of cardiovascular system of spontaneously hypertensive rats
}

\author{
Ima Dovinová ${ }^{1}$, Soňa Čačányiová ${ }^{1}$, Viera Fáberováa ${ }^{2}$ and František Kristek ${ }^{1}$ \\ ${ }^{1}$ Institute of Normal and Pathological Physiology, Centre of Excellence for Cardiovascular Research, Slovak Academy of Sci- \\ ences, Bratislava, Slovakia \\ ${ }^{2}$ Drug Research Institute, Modra, Slovakia
}

\begin{abstract}
The status of nitric oxide (NO) in spontaneously hypertensive rats (SHR) is unclear and its bioavailability may be affected by imbalance with reactive oxygen species. We studied cardiovascular effects of an NO donor, pentaerythrityl tetranitrate (PETN) in SHR. We used Wistar rats, SHR and SHR treated with PETN (100 mg/kg/day). After six weeks, myocardium and aorta from each group were taken for biochemical and iliac artery for functional and morphological study. Long-term administration of PETN to SHR increased cGMP level in platelets and did not affect blood pressure. In myocardium, the therapy resulted in a decrease in cardiac hypertrophy and MDA level, and the increased antioxidant enzyme activity of superoxide dismutase (SOD) and glutathione peroxidase (GPx). In aorta, PETN decreased the NO-synthase activity and had no affect on the enzyme activities of SOD and GPx or on MDA level. In the iliac artery, the endothelium-dependent relaxation to acetylcholine was slightly improved and the maximum vasoconstriction to noradrenaline was decreased. Wall thickness, cross-sectional area, inner diameter, and wall thickness/ inner diameter measured after perfusion fixation $(120 \mathrm{mmHg})$ were not affected. The small effect of PETN on cardiovascular system suggests that NO deficiency is probably not the main cause of pathological alterations in SHR.
\end{abstract}

Key words: Spontaneously hypertensive rat - NO donor - Antioxidant enzyme activity - Vasoreactivity and morphometry - Cardiovascular system

\section{Introduction}

In spite of many experiments, the pathophysiological background of cardiovascular alterations in the spontaneously hypertensive rat (SHR) remains unknown. It is likely that a decline in the production of vasodilatory substances is one of the factors evoking functional and structural alterations in the SHR. The data on production and on the role in these processes of the most potent vasodilator, nitric oxide (NO), are inconsistent. Decreased endothelium-dependent relaxation was found in coronary arteries and in the mesenteric artery (DeMey and Gray 1985; Lüscher 1990; Pourageaud

Correspodence to: Ima Dovinová, Institute of Normal and Pathological Physiology, Slovak Academy of Sciences, Sienkiewiczova 1,81371 Bratislava, Slovakia

E-mail: ima.dovinova@savba.sk and Freslon 1995). Decreased NO production was also found in culture smooth muscle cells of SHR using a direct NO determination (Malinski et al. 1993). Contrary to these findings, an increased endothelium-dependent relaxation in aorta, carotid, and coronary arteries in SHR was reported (Mourlon-Le Grand et al. 1992; Papapetropoulos et al. 1994; Tschudi et al. 1994).

Our previous experiments revealed that a long-term increase in $\mathrm{NO}$ level due to administration of NO donors prevented the development of functional and structural alterations evoked by NO deficiency. In those experiments, we used nitrate tolerance devoid NO donors, pentaerythrityl tetranitrate (PETN) (Kristek 2000) and molsidomine (Kristek et al. 2003). On the other hand, administration of these substances to adult SHR evoked no effect on blood pressure and geometry of the thoracic aorta, carotid and coronary arteries. In vivo (Minami et al. 1995) and in vitro studies on 
conduit arteries (Török and Kristek 2002) showed no differences in the responses to acetylcholine compared to arteries from control Wistar rats. These contradictory results imply that the theories on the role of $\mathrm{NO}$ in the cardiovascular system of SHR are still somewhat speculative.

Enhanced oxidative stress is involved in mediating the endothelial dysfunction and cardiac hypertrophy associated with genetic hypertension. There is growing evidence that reactive oxygen species function as an important intracellular and intercellular second messenger. It has been documented that even subtle changes in the balance between oxidant and antioxidant properties play an important role in maintaining vascular function and structural integrity of the arterial wall (Zalba et al. 2001; Dröge 2002; Stephens et al. 2008).

Changes in activities of antioxidant enzymes in the cardiovascular system were found in SHR. In myocardium, activities of glutation peroxidase (GPx), mitochondrial superoxide dismutase (MnSOD) and cytosolic superoxide dismutase (CuZnSOD) were increased and can be responsible for protection and better adaptation to excess oxidative stress (Csonka et al. 2000). A similar situation was found in aorta, where endothelial NOS, CuZnSOD, MnSOD, and GPx, but not catalase (CAT) levels and activities were increased (Ulker et al. 2003; Racasan et al. 2005). In humans, superoxide dismutase activity was related to the presence of cardiac enlargement and the degree of cardiac histological damage (Fatjó et al. 2005).

PETN represents an effective and tolerance devoid NO donor, which does not induce oxidative stress even after long-term administration. It has been shown to be tolerance-devoid exogenous NO donor (Fing and Basenge 1997) and it was found to be the most active drug in cGMP activation (Hinz et al. 1998; Mollnau et al. 2005). $100 \mathrm{mg}$ PETN were administered to 24 healthy male volunteers. Plasma samples contained concentrations of unchanged PETN or of its metabolite pentaerithrityl trinitrate, in limit of 50 $\mathrm{pg} / \mathrm{ml}$. PE-di-N were reached cca. $3 \mathrm{~h}$ after application of tablets or trituration. The plasma elimination half-life was 4-5 $\mathrm{h}$ and for PE-mono-N levels were observed at $7 \mathrm{~h}$ post application. They declined with a half-life of 10-11 h (Weber et al. 1995).

The aim of our study was to investigate whether long-term administration of exogenous NO donor PETN affected: i) blood pressure, ii) oxidative stress and activities of antioxidant enzymes in the heart and arterial walls, iii) the reactivity and geometry of iliac artery in SHR.

\section{Materials and Methods}

All procedures followed the guidelines set out in the Guide for the Use of Laboratory Animals (Ethics Committee for Experimental Work, Slovak Academy of Sciences, 1995).
The animals were housed at a temperature of $22-24^{\circ} \mathrm{C}$, two animals were in one cage under a 12-h light: dark cycle and fed a regular pellet diet. The experiments lasted six weeks.

Ten-week-old male SHR (Charles river) (285-300 g) were taken for the study. The animals were divided randomly into two groups of twenty animals. The first group of SHR received tap water and the second group received PETN (Dipharma, Italy) at the concentration of $50 \mathrm{mg} / \mathrm{kg}$ twice daily (in the morning and afternoon) p.o. by gavage, with the total daily dose of $100 \mathrm{mg} / \mathrm{kg}$. PETN and the prepared aqueous solution for administration was stored in dark vials. In both groups, systolic blood pressure was measured weekly by the indirect tail plethysmographic method.

At the end of the experiments, eight animals of each group were used for functional and biochemical study, and twelve animals from each group for morphological investigation.

\section{Biochemical studies}

\section{Determination of antioxidant enzyme activities and MDA level}

For antioxidant enzyme assays and MDA assay, $60 \mathrm{mg}$ of the whole aorta with the left iliac artery or the heart were homogenized in 5 to $10 \mathrm{ml}$ of $20 \mathrm{mmol} / \mathrm{l}$ HEPES buffer, $\mathrm{pH}$ 7.2 , containing EGTA ( $1 \mathrm{mmol} / \mathrm{l})$, manitol $(210 \mathrm{mmol} / \mathrm{l})$ and sucrose $(70 \mathrm{mmol} / \mathrm{l})$ per gram tissue. Centrifuged at 1500 $\times g$ for $5 \mathrm{~min}$ at $4^{\circ} \mathrm{C}$. The supernatant was used for all determinations. Proteins from homogenates were determined by a Protein assay kit (Sigma).

Activities of SOD and GPx were determined by standard kits. SOD and GPx activities were assayed in supernatants spectrophotometrically with RANSOD and RANSEL kits (Randox, UK). SOD activity was expressed as the amount of protein causing a $50 \%$ inhibition of formazan dye (505 $\mathrm{nm})$, employing xanthine and xanthine oxidase to generate superoxide radicals. GPx activities were calculated following NADPH oxidation at $340 \mathrm{~nm}$ using cumene hydroperoxide as the substrate.

CAT activity was determined spectrophotometrically according Aebi (1984). The activity was determined by monitoring the decomposition of $\mathrm{H}_{2} \mathrm{O}_{2}$ at $240 \mathrm{~nm}$. Absorbances read at $240 \mathrm{~nm}$ were expressed in calculated activities of $\mathrm{U} / \mathrm{mg}$ protein.

MDA level was measured in tissue homogenates by the thiobarbituric acid reactivity assay. MDA determination was based on the method described by Bird et al. (1982). MDA reacts with thiobarbituric acid to give a red complex, which was determined spectrophotometrically at $535 \mathrm{~nm}$.

\section{NOS activity assay}

NOS activity was determined in crude homogenates of aortas by measuring the formation of $[3 \mathrm{H}]-\mathrm{L}$-citrulline 
from $[3 \mathrm{H}]$-L-arginine, as previously described by Brendt and Snyder (1990). Briefly, 10\% homogenates $(50 \mu \mathrm{l})$ were incubated in $50 \mathrm{mmol} / \mathrm{l}$ Tris/ $\mathrm{HCl}, \mathrm{pH}$ 7.4, [3H]-L-arginine $(10 \mu \mathrm{mol} / \mathrm{l}$, specific activity $5 \mathrm{GBq} / \mathrm{mmol})$ with cofactors calmodulin (30 nmol/l), $1 \mathrm{mmol} / \mathrm{l} \beta \mathrm{NADPH}(1 \mathrm{mmol} / \mathrm{l})$, tetrahydrobiopterin dihydrochloride $(3 \mu \mathrm{mol} / \mathrm{l})$ and $\mathrm{CaCl}_{2}$ $(2 \mathrm{mmol} / \mathrm{l})$ in $100 \mu \mathrm{l}$ of total volume. After $20 \mathrm{~min}$ incubation at $37^{\circ} \mathrm{C}$, the reaction was stopped with $1 \mathrm{ml}$ of $20 \mathrm{mmol} / \mathrm{l}$ HEPES buffer ( $\mathrm{pH}$ 5.5) containing EDTA ( $2 \mathrm{mmol} / \mathrm{l})$, EGTA $(2 \mathrm{mmol} / \mathrm{l})$ and L-citrulline $(1 \mathrm{mmol} / \mathrm{l})$. The samples were applied to $1 \mathrm{ml}$ Dowex 50WX-8 columns. [3H]-L-citrulline was eluted by $1 \mathrm{ml}$ of water and determined by liquid scintillation counting.

\section{Determination of cGMP concentration}

cGMP level was determined in platelets as described by Fink and Bassenge (1997), with some modification. Briefly, blood was drawn into a solution consisting of sodium citrate $(8.5 \mathrm{mmol} / \mathrm{l})$, glucose monohydrate $(10 \mathrm{mmol} / \mathrm{l})$, citric acid (20 mmol/l), acetylsalicylic acid $(0.1 \mathrm{mmol} / \mathrm{l}), 3$-isobutyl1 -methylxantine $(0.1 \mathrm{mmol} / \mathrm{l})$. Platelet-rich plasma was obtained by centrifugation $(160 \times g, 10 \mathrm{~min})$, the fraction was centrifuged $(450 \times g, 15 \mathrm{~min})$ and cells were washed in HEPES buffer (pH 7.4). Platelets were counted microscopically and cGMP concentration was determined using a RIAkit (Amersham). cGMP radioimmunoassay was based on the competition between succinylated cGMP of the sample and [125I]-labeled tracer for binding to polyclonal antibody coated onto tubes. The cGMP concentration was assessed using a gamma counter and the concentrations were calculated from the standard curve.

\section{Toxicity evaluation}

Activity of the lysosomal enzyme $\mathrm{N}$-acetyl- $\beta$-D-glucosaminidase (NAG) was evaluated in tissues from rats $(50-60 \mathrm{mg}$ ) homogenised with Ultra-Turrax in phosphate buffer solution, $\mathrm{pH}$ 7.4, containing $0.1 \%$ Triton $\mathrm{X}-100$. The remaining homogenate was centrifuged at $15,000 \times g$ for $20 \mathrm{~min}$. NAG activity was determined using $12 \mathrm{mmol} / \mathrm{l} \mathrm{p}$-nitrophenyl $\mathrm{N}$-acetyl- $\beta$-D-glucosaminide in $1 \mathrm{~mol} / \mathrm{l}$ citrate buffer (Rao 1981) and p-nitrophenyl was used as standard.

\section{Functional study}

After sacrificing (decapitation), the right iliac artery was excised, cleaned of connective tissue and cut into rings (3-4 $\mathrm{mm}$ in length). The rings were vertically fixed in incubation organ bath with Krebs solution and the changes in isometric tension were recorded as described previously (Čačányiová et al. 2006). The relaxant responses were followed on the rings pre-contracted with maximal dose of phenylephrine $\left(10^{-5} \mathrm{~mol} / \mathrm{l}\right)$ to produce a stable plateau of contraction. The rings were then exposed to cumulative doses of acetylcholine $\left(10^{-8}-10^{-5} \mathrm{~mol} / \mathrm{l}\right)$. The extent of relaxation of arterial rings was expressed as a percentage of the phenylephrine-induced contraction. Maximum contractile responses were induced by phenylephrine $\left(10^{-5} \mathrm{~mol} / \mathrm{l}\right)$ and expressed as the developed tension per cross-sectional area of tisue $\left(\mathrm{mN} \cdot \mathrm{mm}^{-2}\right)$.

\section{Structural investigation}

The animals were sacrificed by an overdose of anesthesia. The chest was opened and the cardiovascular system was perfused via the left ventricle with glutaraldehyde fixative (300 mmol/l glutaraldehyde in $100 \mathrm{mmol} / \mathrm{l}$ phosphate buffer, $\mathrm{pH}$ 7.2-7.4) at a constant perfusion pressure of $120 \mathrm{mmHg}$ for $10 \mathrm{~min}$. After perfusion, the iliac artery was excised, cleaned, sectioned into segments about $1 \mathrm{~mm}$ long and processed according to standard electron microscopic procedure (for more details, see Kristek 2000). Two randomly selected blocks of the artery were cut perpendicularly to the longitudinal axis. Inner circumference and arterial wall thickness (tunica intima + tunica media) of individual vessels were measured on semi-thin sections under a light microscope. From these data, the cross sectional area (tunica intima + tunica media) of the arterial wall and the inner diameter of the corresponding vessel were calculated.

\section{Statistical analysis}

All parameters were expressed as mean \pm S.E.M. Anova and the Bonferroni test for unpaired variables were used for statistical evaluation. Values were considered to be significant at $p<0.05$.

\section{Results}

\section{General hemodynamic parameters}

At the end of the experiment, blood pressure of Wistar rats was $127 \pm 1.4 \mathrm{mmHg}$, while in age-matched SHR it was significantly higher, $214 \pm 7.3 \mathrm{mmHg}(p<0.01)$. Sixweeks administration of PETN to SHR did not significantly change blood pressure $(220 \pm 2.5 \mathrm{mmHg})$ in comparison to untreated SHR. It was significantly higher than in controls.

The heart weight/body weight ratio $(\mathrm{mg} / \mathrm{g})$ in Wistar rats was $3.22 \pm 0.02$, in SHR it was $4.97 \pm 0.16(p<0.01)$. In SHR after the treatment with PETN it was $4.38 \pm 0.03$ $(p<0.05)$, indicating a decrease in cardiac hypertrophy. Nevertheless, there was still a significant difference between the SHR+PETN group and normotensive Wistar rats $(p<$ 0.01 ). 
Table 1. Antioxidant enyzmes activities and oxidative injury in heart (A) and arterial wall (B) in SHR and after the treatment with PETN

A

\begin{tabular}{|l|c|c|}
\hline & $\begin{array}{c}\text { SHR } \\
(n=8)\end{array}$ & $\begin{array}{c}\text { SHR+PETN } \\
(n=8)\end{array}$ \\
\hline $\begin{array}{l}\text { SOD } \\
(\mathrm{U} / \mathrm{mg} \text { protein })\end{array}$ & $0.53 \pm 0.019$ & $0.84 \pm 0.049^{++}$ \\
\hline $\begin{array}{l}\text { CAT } \\
(\mathrm{U} / \mathrm{mg} \text { protein) }\end{array}$ & $0.089 \pm 0.0056$ & $0.048 \pm 0.0032^{++}$ \\
\hline $\begin{array}{l}\text { GPx } \\
(\mathrm{U} / \mathrm{mg} \text { protein) }\end{array}$ & $0.0618 \pm 0.0095$ & $0.110 \pm 0.013^{+}$ \\
\hline $\begin{array}{l}\text { MDA } \\
\text { (nmol/mg protein) }\end{array}$ & $3.02 \pm 0.13$ & $1.29 \pm 0.16^{++}$ \\
\hline
\end{tabular}

B

\begin{tabular}{|l|c|c|}
\hline & $\begin{array}{c}\text { SHR } \\
(n=8)\end{array}$ & $\begin{array}{c}\text { SHR+PETN } \\
(n=8)\end{array}$ \\
\hline $\begin{array}{l}\text { SOD } \\
(\mathrm{U} / \mathrm{mg} \text { protein) }\end{array}$ & $0.31 \pm 0.031$ & $0.32 \pm 0.026$ \\
\hline $\begin{array}{l}\text { GPx } \\
(\mathrm{U} / \mathrm{mg} \text { protein) }\end{array}$ & $0.031 \pm 0.011$ & $0.024 \pm 0.0039$ \\
\hline $\begin{array}{l}\text { MDA } \\
\text { (nmol/mg protein) }\end{array}$ & $1.78 \pm 0.15$ & $2.12 \pm 0.18$ \\
\hline
\end{tabular}

Values are \pm S.E.M. $n$, number of rats; SOD, superoxid dismutase; CAT, catalase; GPx, glutathione peroxidase; MDA, malondyaldehyde; ${ }^{+} p<0.05,{ }^{++} p<0.01$ with respect to the value of SHR group.

\section{Biochemical studies}

Oxidative injury and activity of antioxidant enzymes in the heart and in vessel walls

Long-term administration of PETN evoked a decrease in oxidative injury. MDA level in the heart decreased by $38 \%$ $(p<0.01)$. At the end of the experiment, significant changes in the activity of antioxidant enzymes were observed in heart homogenates. SOD activity and activity of GPx were elevated by $54 \%(p<0.01)$ and by $78 \%(p<0.05)$, respectively, while CAT activity decreased by $48 \%(p<0.01)$. For further details, see Table 1A. No significant changes were observed in SOD and GPx activities in aorta. Oxidative injury of aorta, as measured by MDA level, was unchanged (Table 1B).

\section{cGMP level and NOS activity}

The value of cGMP measured in platelets was significantly elevated by $330 \%(p<0.05)$ in the SHR+PETN group compared with SHR. The NOS activity in arterial wall was significantly decreased after PETN administration compared to the SHR group by $14 \%(p<0.05$, see Table 2$)$.

\section{Toxicity of PETN administration}

Toxicity of a cumulative dose of $200 \mathrm{mg} / \mathrm{kg} /$ day of PETN to SHR was evaluated in kidney, heart and liver. Activity of the lysosomal enzyme NAG indicated no changes or elevations (see Table 3).

\section{Functional evaluation}

In Wistar rats, acetylcholine $\left(10^{-8}-10^{-5} \mathrm{~mol} / \mathrm{l}\right)$ induced concentration-dependent relaxation of the iliac artery precontracted by phenylephrine $\left(10^{-5} \mathrm{~mol} / \mathrm{l}\right)$, with maximum of $74.24 \pm 8.57 \%$. In SHR, a clear-cut attenuation of relaxation was found and the maximum reached only $12.14 \pm 3.60 \%$ $(p<0.01)$. The chronic treatment with PETN moderately, yet significantly improved the dose-dependent acetylcholine-induced relaxation of the iliac artery. The maximum relaxation in the PETN-treated group was $37.13 \pm 1.90 \%$ $(p<0.01$, Figure 1). In Wistar rats, the single bolus of phenylephrine $\left(10^{-5} \mathrm{~mol} / \mathrm{l}\right)$ induced the maximum contraction of $1.23 \pm 0.15 \mathrm{mN} \cdot \mathrm{mm}^{-2}$ of isolated iliac artery, which increased in the SHR group to $3.06 \pm 0.35 \mathrm{mN} \cdot \mathrm{mm}^{-2}(p<$ 0.05). After treatment with PETN, the contraction induced by phenylephrine significantly decreased compared to SHR $\left(2.01 \pm 0.35 \mathrm{mN} \cdot \mathrm{mm}^{-2}, p<0.05\right.$, Figure 2$)$.

Table 2. Changes in cGMP level and NO-synthase activity in SHR and after PETN administration

\begin{tabular}{|l|c|c|}
\hline & $\begin{array}{c}\text { SHR } \\
(n=8)\end{array}$ & $\begin{array}{c}\text { SHR+PETN } \\
(n=8)\end{array}$ \\
\hline $\begin{array}{l}\text { cGMP (platelet) } \\
\left(\mathrm{pmol} / 10^{9}\right)\end{array}$ & $0.104 \pm 0.019$ & $0.349 \pm 0.063^{+}$ \\
\hline $\begin{array}{l}\text { NOS activity (aorta) } \\
(\mathrm{dpm} / \mu \mathrm{g} / \mathrm{min})\end{array}$ & $51.63 \pm 1.97$ & $45.87 \pm 1.37^{+}$ \\
\hline
\end{tabular}

Values are \pm S.E.M. $n$, number of rats; cGMP, cyclic guanosine monophosphate; NOS, nitric oxide synthase; ${ }^{+} p<0.05$ with respect to the value of SHR group.

Table 3. Evaluation of toxicity by lysosomal enzyme NAG in different rat tissues in SHR and after the treatment with PETN

\begin{tabular}{|l|c|c|}
\hline \multirow{2}{*}{ Tissue } & \multicolumn{2}{|c|}{ NAG activity } \\
& $\begin{array}{c}\text { SHg of } \mathrm{p}-\text { nitrophenol/min/mg protein) } \\
(n=8)\end{array}$ & $\begin{array}{c}\text { SHR+PETN } \\
(n=8)\end{array}$ \\
\hline Kidney & $15.19 \pm 0.41$ & $14.85 \pm 0.38$ \\
\hline Heart & $2.77 \pm 0.08$ & $2.83 \pm 0.15$ \\
\hline Liver & $7.52 \pm 0.22$ & $7.35 \pm 0.19$ \\
\hline
\end{tabular}

Values are \pm S.E.M. $n$, number of rats; NAG, N-acetyl- $\beta$-D-glucosaminidase. 


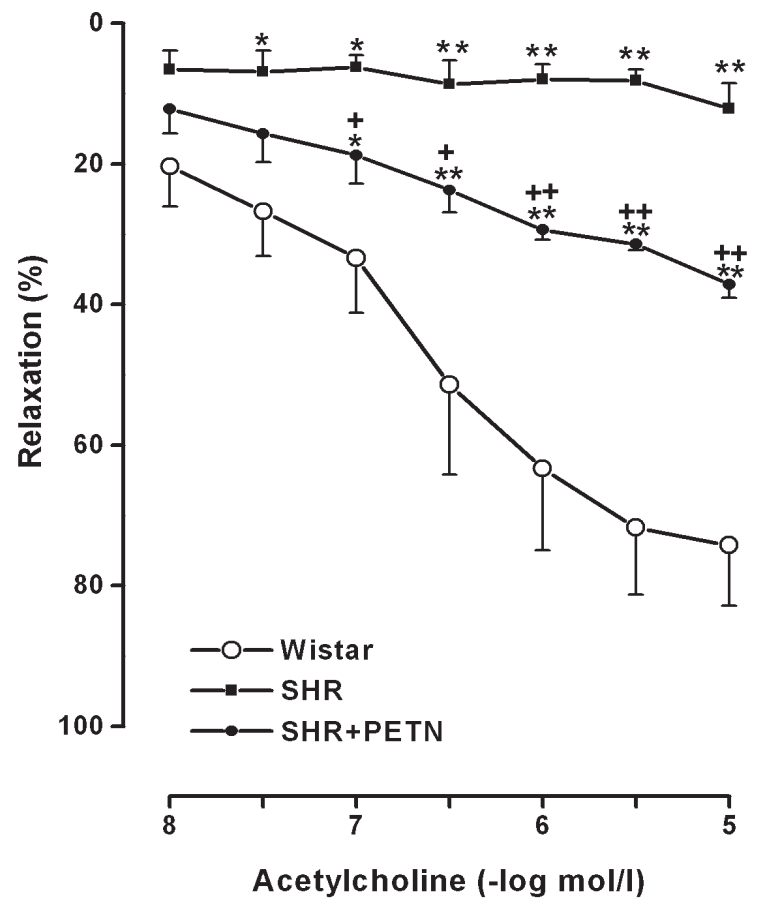

Figure 1. Concentration-response curves to acetylcholine in the isolated iliac artery of normotensive (Wistar, $n=8$ ) rats, and in spontaneously hypertensive rats before (SHR, $n=8)$ and after (SHR+PETN, $n=8$ ) the long-term treatment with pentaerythrityl tetranitrate. ${ }^{*} p<$ $0.05,{ }^{* *} p<0.01$ with respect to the value of Wistar group; ${ }^{+} p<0.05$, ${ }^{++} p<0.01$ with respect to the value of SHR group.

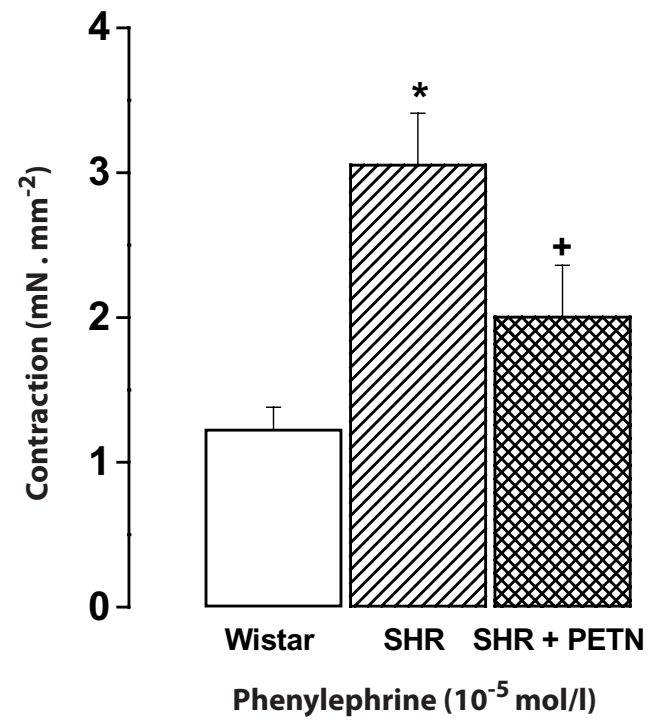

Figure 2. Maximal phenylephrine-induced contractile responses of isolated iliac artery in normotensive (Wistar, $n=8$ ) rats, and in spontaneously hypertensive rats before (SHR, $n=8$ ) and after $(\mathrm{SHR}+\mathrm{PETN}, n=8)$ the long-term treatment with pentaerythrityl tetranitrate. ${ }^{\star} p<0.05$ with respect to the value of Wistar group, ${ }^{+} p<0.05$ with respect to the value of SHR group.

\section{Morphological study}

Morphological observation of the iliac artery revealed that wall thickness, cross-sectional area (arterial wall mass), inner diameter, and wall thickness/inner diameter ratio of normotensive rats were significantly increased in comparison with the SHR and SHR+PETN groups $(p<0.01)$. No difference in this respect was observed between the SHR and SHR+PETN group (Table 4).

\section{Discussion}

The main findings of the present study were that long-term administration of PETN to SHR revealed different effects of treatment in the heart and in vessel walls. The observed significant increase in cGMP content in platelets proved the finding of Fink and Basenge (1987) that PETN is a tolerancedevoid NO donor. There is still an open question why PETN did not reduce blood pressure in SHR, though it improved cardiac hypertrophy and antioxidant status of heart. Contrary to the heart, vasorelaxation of iliac artery was slightly improved but antioxidant activity in arterial walls was not affected. Similar results were found after tempol administration (Yanes et al. 2005): tempol reduced oxidative stress in the presence or absence of NO, but it was not able to reduce blood pressure in the absence of NO. These data suggest that, in hypertensive individuals, antioxidants may be able to reduce oxidative stress but not blood pressure. The pharmacological effects of PETN in vivo are most probably mediated by $\mathrm{NO}$ and have several potentially antiatherosclerotic vascular activities (Hacker et al. 2001).

The significant decrease in NOS activity in the present study could at least partially explain the low effect of PETN. Inhibitory effect of NO donors on NOS activity has been reported (Bult et al. 1991; Rengasamy and Johns 1993), so we suggest that the expected increase in NO level induced by PETN may act as a negative feedback on NOS activity, so that the NO may be kept approximately at the same or on a slightly higher level then in the SHR. A higher level of NO could decrease cardiac hypertrophy (as we have found), since NO is a proven antiproliferative agent (Arnal et al. 1994). The benefit of the decreased cardiac hypertrophy by PETN is, however, controversial, since the decreased myocardial mass has to cope with similar resistance as in untreated SHR. This effect was not observed in iliac artery: the arterial wall mass was not reduced. Moreover, the endothelium-dependent relaxation of iliac artery to acetylcholine was significantly improved, thought still significantly reduced in comparison with normotensive Wistar rats. NO-sensitive part cannot be fully responsible for the slightly improved endothelial-dependent relaxation, since acetylcholine and NO donors themselves are able to 
Table 4. Geometry of iliac artery in Wistar and SHR before and after the treatment with PETN

\begin{tabular}{|l|c|c|c|}
\hline & $\begin{array}{c}\text { Wistar } \\
(n=12)\end{array}$ & $\begin{array}{c}\text { SHR } \\
(n=12)\end{array}$ & $\begin{array}{c}\text { SHR+PETN } \\
(n=12)\end{array}$ \\
\hline $\mathrm{WT}(\mu \mathrm{m})$ & $28.99 \pm 2.09$ & $54.12 \pm 2.00^{\star *}$ & $53.78 \pm 2.85^{* *}$ \\
\hline $\mathrm{CSA} \times 10^{3}\left(\mu \mathrm{m}^{2}\right)$ & $77.00 \pm 4.64$ & $123.00 \pm 6.30^{\star *}$ & $110.00 \pm 4.50^{* *}$ \\
\hline $\mathrm{ID}(\mu \mathrm{m})$ & $828.00 \pm 28.00$ & $680.00 \pm 46.00^{* *}$ & $601.00 \pm 16.00^{* *}$ \\
\hline $\mathrm{WT} / \mathrm{ID} \times 10^{-2}$ & $3.59 \pm 0.36$ & $8.65 \pm 0.91^{\star *}$ & $9.06 \pm 0.69^{* *}$ \\
\hline
\end{tabular}

Values are \pm S.E.M. $n$, number of rats; WT, wall thickness; CSA, cross sectional area; ID, inner diameter; WT/ID, wall thickness/inner diameter ratio; ${ }^{* *} p<0.01$ with respect to the value of Wistar group.

evoke relaxation of conduit arteries via additional regulatory mechanisms, such as hyperpolarization (Corriu et al. 1996). Similarly, other regulatory mechanisms than NO may be engaged in blood pressure regulation, such as the hyperpolarizing factor which was proved to be important in the resistant part of arterial tree (Gerová et al. 2004, 2005; Gerová and Kittová 2006). The morphological observation of iliac artery revealed that PETN administration had no effect on wall thickness, inner diameter, arterial wall mass, and wall thickness/inner diameter ratio. The finding is in good consent with our previous data from the thoracic aorta, carotid and coronary artery (Kristek et al. 2003). Since we did not find hypotrophy of arterial wall, the observed reduction of response to noradrenaline should be associated with an increased total level of NO after PETN treatment, able to partially counteract contractile efficiency. Alternatively, the blunted contraction could also be a result of an increased level of peroxynitrites produced in a reaction of superoxide radicals with increased level of NO; this may lead to compromised smooth muscle cells activity (Paravicini and Touyz 2006) and can also be the reason for unchanged SOD activity in arterial walls.

The examination of some antioxidant enzymes also proved a different effect of PETN on the heart and iliac artery. In the heart, PETN treatment increases SOD activity, indicating increased generation of $\mathrm{O}_{2}$ radicals. SOD catalyses the dismutation of $\mathrm{O}_{2}$ radicals to $\mathrm{H}_{2} \mathrm{O}_{2}$. However, CAT was decreased and GPx increased, both enzymes degrading $\mathrm{H}_{2} \mathrm{O}_{2}$. Since the sum of the CAT and GPx activity is approximately equal, it is possible that $\mathrm{H}_{2} \mathrm{O}_{2}$ degradation was similar as in $\mathrm{SHR}$, but $\mathrm{H}_{2} \mathrm{O}_{2}$ was degraded preferentially via GPx. A significant decrease in MDA indicates a reduction of oxidative stress in the heart after PETN administration.

Contrary to the heart, the same antioxidant enzymes in arterial wall were not affected by PETN treatment (MDA, SOD, GPx). It has been demonstrated that, in endothelial cells, active PETN protects endothelium via the antioxidant defense protein heme oxygenase 1 (HO-1) (Oberle 2003), the increased HO-1 expression and the ensuing formation of billirubin and $\mathrm{CO}$ may contribute to and explain the specific antioxidant and antiatherogenic actions of PETN.

Increased activities of some antioxidant enzymes in SHR compared with normotensive rats either in myocardium or in vessel wall have been reported. In aorta, eNOS, CuZnSOD, MnSOD, and GPx, but not CAT, protein levels and activities were increased (Ulker et al. 2003; Racasan et al. 2005). In myocardium, activities of GPx, MnSOD, CuZnSOD and also NOS activity were elevated (Csonka et al. 2000; Janega et al. 2007). In both, the antioxidant enzymes can be responsible for protection and better adaptation of excess oxidative stress in SHR. Our study indicates that the increased level of NO due to PETN administration resulted in an antioxidant protection only in myocardium, while antioxidant activity of arterial walls was not affected. Nevertheless, the low activity of PETN in arterial walls is consistent with a slight functional improvement of acetylcholine-dependent relaxation and with the morphological findings showing unchanged geometry of the iliac artery.

Based on biochemical, physiological, and morphological investigations, the present study revealed negligible effects on vascular antioxidant activities, reactivity, and morphology. However, it revealed an improvement to heart oxidative injury and hypertrophy as well as of antioxidant status. A long-term increase in $\mathrm{NO}$ level due to administration of exogenous NO donor only marginally, if any, affected the alterations in cardiovascular system of SHR. It suggests that the pathological changes in cardiovascular system of SHR are probably not evoked by NO deficiency.

Acknowledgments. Financial support by Slovak VEGA 2/6139/28, VEGA 2/0066/08 grant agencies is gratefully acknowledged. We thank L. Kosnáčová for her technical assistance and Y. Hanáčková for help with housing the animals.

\section{References}

Aebi H. (1984): Catalase in vitro. Methods Enzymol. 105, 125-126

Arnal J. F., Yamin J., Dockery S., Harrison D. G. (1994): Regulation of endothelial nitric oxide synthase mRNA, protein, and 
activity during cell growth. Am. J. Physiol., Cell Physiol. 267, C1381-388

Bird R. P., Drapper H. H., Valli V. E. (1982): Toxicological evaluation of malondialdehyde: a 12-month study of mice. J. Toxicol. Environ. Health 10, 897-905

Brendt D. S., Snyder S. H. (1990): Isolation of nitric oxide synthetase, a calmodulin-requiring enzyme. Proc. Natl. Acad. Sci. U.S.A. 87, 682-685

Bult H., DeMeyer G. R. Y., Jordaens F. H., Herman A. G. (1991): Chronic exposure to exogenous nitric oxide may suppress its endogenous release and efficacy. J. Cardiovasc. Pharmacol. 17 (Suppl. 3), S79-82

Čačányiová S., Cebová M., Kuneš J., Kristek F. (2006): Comparison of vascular function and structure of iliac artery in spontaneously hypertensive and hereditaryhypertriglyceridemic rats. Physiol. Res. 55 (Suppl. 1), S73-80

Corriu C., Félétou M., Canet E., Vanhoutte P. M. (1996): Endothelium-derived factors and hyperpolarization of the carotid artery of guinea-pig. Br. J. Pharmacol. 119, 959-964

Csonka C., Pataki T., Kovacs P., Muller S. L., Schroeter M. L., Tosaki A., Blasig I. E. (2000): Effects of oxidative stress on the expression of antioxidative defense enzymes in spontaneously hypertensive rat hearts. Free Radic. Biol. Med. 29, 612-619

DeMey J. G., Gray S. (1985): Endothelium-dependent reactivity in resistance vessels. Prog. Appl. Microcirc. 8, 181-187

Dröge W. (2002): Free radicals in the physiological control of cell function. Physiol. Rev. 82, 47-95

Fatjó F., Sancho-Bru P., Fernández-Solà J., Sacanella E., Estruch R. Bataller R., Nicolás J. M. (2005): Up-regulation of myocardial L-type $\mathrm{Ca}^{2+}$ channel in chronic alcoholic subjects without cardiomyopathy. Alcohol. Clin. Exp. Res. 31, 1099-1105

Fink B., Bassenge E. (1997): Unexpected, tolerance-devoid vasomotor and platelet actions of pentaerythrityl tetranitrate. J. Cardiovasc. Pharmacol. 30, 831-836

Gerová M., Török J., Pecháňová, O., Matušková, J. (2004): Rilmenidine prevents blood pressure increase in rats with compromised nitric oxide production. Acta Pharmacol. Sin. 25, 1640-1646

Gerová M., Kristek F., Čačányiová S., Cebová M. (2005): Acetylcholine and bradykinin enhance hypotension and affect the function of remodeled conduit arteries in SHR and SHR treated with nitric oxide donors. Braz. J. Med. Biol. Res. 38, 959-966

Gerová M., Kittová M. (2006): Systemic blood pressure response to the inhibition of two hyperpolarizing pathways: a comparison to NO-synthase inhibition. Physiol. Res. 55, 603-610

Hacker A., Müller S., Meyer W., Kojda G. (2001): The nitric oxide donor pentaerythritol tetranitrate can preserve endothelial function in established atherosclerosis. Br. J. Pharmacol. 132, 1707-1714

Hinz B., Kuntze U., Schröder H. (1998): Pentaerithrityl tetranitrate and its phase I metabolites are potent activators of cellular cyclic GMP accumulation. Biochem. Biophys. Res. Commun. 253, 658-661
Janega P., Kojšová S., Jendeková L., Babál P., Pecháňová O. (2007): Indapamide-induced prevention of myocardial fibrosis in spontaneous hypertension rats is not nitric oxide-related. Physiol. Res. 56, 825-828

Kristek F. (2000): Pentaerythrityl tetranitrate could prevent structural changes in conduit arteries evoked by longterm NO-synthase inhibition. Br. J. Pharmacol. 130, 450-456

Kristek F., Fáberová V., Varga I. (2003): Long-term effect of molsidomine and pentaerythrityl tetranitrate on cardiovascular system of spontaneously hypertensive rats. Physiol. Res. 52, 709-717

Lüscher T. F. (1990): The endothelium: target and promoter of hypertension? Hypertension 15, 482-485

Malinski T., Kapturczak M., Dayharsh J., Bohr D. (1993): Nitric oxide synthase activity in genetic hypertension. Biochem. Biophys. Res. Commun. 194, 654-568

Minami N., Imai Y., Hashimoto J., Abe K. (1995): Contribution of nitric oxide to basal blood pressure in concious spontaneously hypertensive rats and normotensive Wistar Kyoto rats. Clin. Sci. 89, 177-182

Mollnau H., Oelze M., August M., Wendt M., Daiber A., Schulz E., Baldus S., Kleschyov A. L., Materne A., Wenzel P., Hink U., Nickenig G., Fleming I., Munzel T. (2005): Mechanisms of increased vascular superoxide production in an experimental model of idiopathic dilated cardiomyopathy. Arterioscler. Thromb. Vasc. Biol. 25, 2554-2559

Mourlon-Le Grand M. C., Benessiano J., Levy B. I. (1992): cGMP pathway and mechanical properties of carotid artery wall in WKY rats and SHR: role of endothelium. Am. J. Physiol., Heart Circ. Physiol. 263, H61-67

Oberle S., Abate A., Grosser N., Hemmerle A., Vreman H. J., Dennery P. A., Heinz T., Schneider H. T., Stalleicken D., Schroder H. (2003): Endothelial protection by pentaerithrityltrinitrate: bilirubin and carbon monoxide as possible mediators. Exp. Biol. Med. 228, 529-534

Papapetropoulos A., Marczin N., Snead M. D., Cheng C., Milici A., Cantravas J. D. (1994): Smooth muscle responsiveness to nitrovasodilators in hypertensive and normotensive rats. Hypertension 23, 76-484

Paravicini T. M., Touyz R. M. (2006): Redox signaling in hypertension (Review). Cardiovasc. Res. 71, 147-158

Pourageaud F., Freslon J. L. (1995): Endothelial smooth muscle properties of coronary and mesenteric resistance arteries in spontaneously hypertensive rats compared to WKY rats. Fundam. Clin. Pharmacol. 9, 37-45

Racasan S., Braam B., Koomans H. A., Joles J. A. (2005): Programming blood pressure in adult SHR by shifting perinatal balance of $\mathrm{NO}$ and reactive oxygen species toward $\mathrm{NO}$ : the inverted Barker phenomenon. Am. J. Physiol., Renal Physiol. 288, R626-636

Rao G. M. (1981): Effect of genetic diabetes on $\beta$-N-acetylglucosaminidase activity in plasma, conjunctiva, muscle and kidney cortex in mice. Biomedicine 35, 159-161

Rengasamy A., Johns R. A. (1993): Regulation of nitric oxide synthase by nitric oxide. Mol. Pharmacol. 44, 124-128

Stephens J. W., Khanolkar M. P., Bain S. C. (2008): The biological relevance and measurement of plasma markers of 
oxidative stress in diabetes and cardiovascular disease. Atherosclerosis 202, 321-329

Török J., Kristek F. (2002): Beneficial effect of pentaerythrityl tetranitrate on functional and morphological changes in the rat thoracic aorta evoked by long-term nitric oxide synthase inhibition. Vascul. Pharmacol. 38, 177-182

Tschudi M., Crisciona L., Novosel D., Pfeiffer K., Lüscher T. (1994): Antihypertensive therapy augments endothelium-dependent relaxations in coronary arteries of spontaneously hypertensive rats. Circulation 98, 2212-2218

Ulker S., McMaster D., McKeown P. P., Bayraktutan U. (2003): Impaired activities of antioxidant enzymes elicit endothelial dysfunction in spontaneous hypertensive rats despite enhanced vascular nitric oxide generation. Cardiovasc. Res. 59, 488-500

Weber W., Michaelis K., Luckow V., Kuntze U., Stalleicken D. (1995): Pharmacokinetics and bioavailability of pentaerithrityl tetranitrate and two of its metabolites. Arzneimittelforschung 45,781-784

Yanes L., Romero D., Iliescu R., Cucchiarelli V. E., Fortepiani L. A., Santacruz F., Bell W., Zhang H., Reckelhoff J. F. (2005): Systemic arterial pressure response to two weeks of Tempol therapy in SHR: involvement of NO, the RAS, and oxidative stress. Am. J. Physiol., Regul. Integr. Comp. Physiol. 288, R903-908

Zalba G., Jose G. S., Moreno M. U., Fortuno M. A., Fortuno A., Beaumont F. J., Diez J. (2001): Oxidative stress in arterial hypertension - role of $\mathrm{NAD}(\mathrm{P}) \mathrm{H}$ oxidase. Hypertension 38, 1395-1399

Received: September 22, 2008

Final version accepted: January 14, 2009 